\title{
Publisher Correction: SARS-CoV-2 and the brain to be studied long-term
}

\section{Sarah Lemprière}

Nature Reviews Neurology (2020) https://doi.org/10.1038/s41582-020-0405-8 Published online 27 August 2020

The originally published article incorrectly stated that the next Alzheimer's Association International Conference will be held in May 2021. However, the date of the conference has not yet been formally announced. This has been corrected in the HTML and PDF versions of the manuscript.

https://doi.org/10.1038/s41582-020-0407-6 I Published online 3 September 2020

(c) Springer Nature Limited 2020

\section{Author Correction: Zoonotic and vector-borne parasites and epilepsy in low-income and middle-income countries}

Gagandeep Singh (D), Samuel A. Angwafor, Alfred K. Njamnshi, Henry Fraimow and Josemir W. Sander(D)

Nature Reviews Neurology (2020) https://doi.org/10.1038/s41582-020-0361-3 Published online 19 May 2020

In the article originally published online, an arrow was missing from Figure 3. This error has been corrected in the HTML and PDF versions of the article.

https://doi.org/10.1038/s41582-020-0372-0 I Published online 26 May 2020

๑) Springer Nature Limited 2020

\section{Author Correction: Neurological immunotherapy in the era of COVID-19 - looking for consensus in the literature}

\section{Catharina Korsukewitz, Stephen W. Reddel, Amit Bar-Or and Heinz WiendI (D)}

Nature Reviews Neurology (2020) https://doi.org/10.1038/s41582-020-0385-8 Published online 08 July 2020

In the originally published version of this article, the description of the study by Sormani et al. (ref. 14) in the third paragraph of the section entitled 'B cell-depleting therapies' was incorrect. The description should read:

In 232 patients with multiple sclerosis and suspected or proven COVID-19, the severity of COVID-19 was classified as mild (no or mild pneumonia) in 222 (96\%), severe (shortness of breath, respiratory rate $\geq 30$ breaths $/ \mathrm{min}$, blood oxygen saturation $\leq 93 \%, \mathrm{PaO} 2: \mathrm{FiO} 2<300 \mathrm{mmHg} / \%$, and an increase in lung infiltrates of $>50 \%$ within $24-48 \mathrm{~h}$ ) in $4(2 \%)$ and critical (respiratory failure, septic shock and multiple organ dysfunction or failure) in 6 (3\%). Of the 6 patients with critical illness, 1 recovered and 5 died. Of 28 patients receiving a B cell-depleting therapy, 3 (10\%) developed a severe or critical disease course ${ }^{14}$.

This description has been corrected in the HTML and PDF versions of the article.

https://doi.org/10.1038/s41582-020-0392-9 I Published online 22 July 2020

(๑) Springer Nature Limited 2020 